\title{
Sucrose-to-ethanol microalgae-based platform using seawater
}

\author{
Maria Eugenia Sanz Smachetti ${ }^{1}$, Camila Denise Coronel $^{1}$, Graciela L. Salerno, Leonardo Curatti* \\ Instituto de Investigaciones en Biodiversidad y Biotecnología (INBIOTEC-CONICET), Mar del Plata, 7600, Argentina \\ Fundación para Investigaciones Biológicas Aplicadas (FIBA), Mar del Plata, 7600, Argentina
}

A R T I C L E I N F O

\section{Keywords:}

Biofuels

Saccharification

Sugars

Bioethanol

Biorefinery

Water footprint

\begin{abstract}
A B S T R A C T
Microalgal biomass is increasingly considered a promising feedstock for the production of bioethanol because it has simpler biochemical composition and structural features than plant feedstocks. However, it still requires hazardous and/or expensive acid or enzymatic saccharification processes before its conversion into ethanol by fermentation. To bypass this limitation, we identified microalgal strains that accumulate up to $10 \%$ ( $w / \mathrm{w}$ ) of sucrose, a readily fermentable sugar. Conditions were optimized to produce sucrose in half-strength seawater, as well as efficient extraction by very mild procedures, and conversion into ethanol. We present a model based on cultivation in environmental photobioreactors that predicted a productivity of $4200 \mathrm{~L} \mathrm{ethanol \cdot ha}{ }^{-1} \cdot \mathrm{year}^{-1}$ in raceway ponds in Brazil, approaching the average sucrose and ethanol productivity from sugarcane.
\end{abstract}

\section{Introduction}

Bioethanol represents an alternative to diminish rapid depletion of crude oil reserves and climate change [1]. It can be produced by fermentation of renewable agricultural feedstocks rich in sucrose or starch, such as sugarcane or corn, respectively. It is also the most used renewable fuel in the transportation sector [2]. However, sustainability concerns related to food security and environment conservation promoted the development of a second generation of bioethanol from lignocellulosic feedstocks. Yet, the complex chemical composition and structure of these materials demand harsh physicochemical pretreatments and costly enzymes for saccharification, posing a difficult-toovercome barrier towards commercialization [3].

Microalgal biomass is increasingly considered as a promising feedstock for the production of third generation bioethanol because of several characteristics [4,5]. Firstly, microalgae have higher productivity of biomass and starch per unit of surface and time than the most productive crop plants. They have simpler biochemical and structural composition in comparison to plant feedstocks. They can be cultivated independently from arable land and freshwater, with the possibility of using sea or brackish water for cultivation. Also, there is the possibility of using residues from industries as a source of inexpensive nutrients, especially $\mathrm{CO}_{2}, \mathrm{~N}$-sources and phosphates. This could additionally assist in municipal or industrial waste management, to reduce the demand for fertilizers, and to mitigate climate change [5-8].
However, the technology to transform algal biomass into fuels is not mature yet, and thus current capital and production costs are prohibitive for commercialization [9]. Among the aspects that need to be improved are: (i) high, robust, and consistent productivity under dynamic environmental conditions [10]; (ii) although currently superior to crop plants, the freshwater footprint and demand for fertilizers of microalgae cultivation must be further optimized [11]; (iii) biomass harvesting and downstream processes for conversion into biofuels also need improvement [12]. Furthermore, most techno-economic analyses suggest that co-production of biofuels and animal feed, or other high-value co-products, would be mandatory for cost-effectiveness [12].

Some microalgal strains accumulate large quantities of carbohydrates in their biomass, up to $70 \%(w / w)[4,6]$, mainly as insoluble starch and cellulose [6,13]. Although the lack of lignin and simpler structure of microalgal cell walls [14] largely simplifies biomass saccharification in comparison to plant feedstocks, algal biomass still requires chemical (acid or alkaline)/physicochemical or enzymatic hydrolysis to enable fermentation [4,5,7].

Similarly to plants, some microalgae and cyanobacteria accumulate sucrose [15], a soluble sugar that is readily fermentable by yeast and by most industrially relevant microorganisms [16,17]. Sucrose accumulates in cyanobacteria and microalgae as a response to salt, osmotic, desiccation, cold or heat stress $[18,19]$. Recently, several studies have shown increased sucrose accumulation by genetic engineering of unicellular or filamentous cyanobacteria [20-22]. Particularly, we showed the genetic modification of carbohydrates partitioning in a filamentous

\footnotetext{
* Corresponding author at: Instituto de Investigaciones en Biodiversidad y Biotecnología (INBIOTEC), Vieytes 3103, Mar del Plata 7600, Argentina.

E-mail address: lcuratti@inbiotec.conicet.gov.ar (L. Curatti).

${ }^{1}$ These authors contributed equally.
} 
cyanobacterium towards accumulation of sucrose up to $10 \%(w / w)$. After aqueous extraction from the transgenic biomass, sucrose-rich syrups were efficiently converted into ethanol without the need of exhaustive or expensive pretreatments and/or saccharification processes. Additionally, a large fraction of the cyanobacterial protein content could be separated after short pulses of heat, keeping the value of sugars, protein and lipids for different applications in the food, energy and/or other sectors of the market [23].

This study describes the identification of sucrose-accumulating native microalgae in response to $\mathrm{NaCl}$ stress. Conditions were optimized to induce sucrose accumulation up to $10 \%(w / w)$ using seawater. Sucrose was extracted by two alternative methods and directly fermented into ethanol at the maximum theoretical efficiency, leaving a large fraction of crude protein to be recovered for feed purposes. A semi-experimental model for bioethanol production using marine water in open raceway ponds is provided after cultivation simulations in environmental photobioreactors.

\section{Materials and methods}

\subsection{Strains and culture conditions}

The microalgal strains used in this work were obtained from previous bioprospecting efforts from Southeastern Buenos Aires, Argentina $\left(38^{\circ} 0^{\prime} 0^{\prime \prime} \mathrm{S} 57^{\circ} 33^{\prime} 0^{\prime \prime} \mathrm{W}\right)$, in 2010 [24] or Jujuy, Argentina $\left(24^{\circ} 11^{\prime} 08^{\prime \prime} \mathrm{S}\right.$ $65^{\circ} 17^{\prime} 58^{\prime \prime} \mathrm{W}$ ) in 2016 [25].

The reference culture condition was performed in $500 \mathrm{~mL}$ bottles

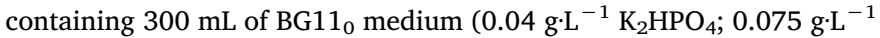
$\mathrm{MgSO}_{4} \cdot 7 \mathrm{H}_{2} \mathrm{O} ; 0.036 \mathrm{~g} \cdot \mathrm{L}^{-1} \mathrm{CaCl}_{2} \cdot 2 \mathrm{H}_{2} \mathrm{O} ; 0.006 \mathrm{~g} \cdot \mathrm{L}^{-1}$ citric acid; $0.006 \mathrm{~g} \cdot \mathrm{L}^{-1}$ ferric ammonium citrate; $0.001 \mathrm{~g} \cdot \mathrm{L}^{-1}$ EDTA (disodium salt); $0.02 \mathrm{~g} \cdot \mathrm{L}^{-1} \mathrm{Na}_{2} \mathrm{CO}_{3}$, and trace metal mix A5 (2.86 mg.L ${ }^{-1} \mathrm{H}_{3} \mathrm{BO}_{3}$; $1.81 \mathrm{mg} \cdot \mathrm{L}^{-1} \mathrm{MnCl}_{2} \cdot 4 \mathrm{H}_{2} \mathrm{O} ; 0.222 \mathrm{mg} \cdot \mathrm{L}^{-1} \mathrm{ZnSO}_{4} \cdot 7 \mathrm{H}_{2} \mathrm{O} ; 0.39 \mathrm{mg} \cdot \mathrm{L}^{-1}$ $\mathrm{NaMoO}_{4} \cdot 2 \mathrm{H}_{2} \mathrm{O} ; 0.079 \mathrm{mg} \cdot \mathrm{L}^{-1} \mathrm{CuSO}_{4} \cdot 5 \mathrm{H}_{2} \mathrm{O}$ and $0.049 \mathrm{mg} \cdot \mathrm{L}^{-1} \mathrm{Co}$ $\left.\left(\mathrm{NO}_{3}\right)_{2} \cdot 6 \mathrm{H}_{2} \mathrm{O}\right)$ ) supplemented with $0.84 \mathrm{~g} \cdot \mathrm{L}^{-1} \mathrm{NaHCO}_{3}$, and $\mathrm{NaCl}$ and $\mathrm{NaNO}_{3}$ as indicated. Bottles were illuminated with constant white light at $540 \mu \mathrm{mol} \cdot \mathrm{photons} \cdot \mathrm{m}^{-2} \cdot \mathrm{s}^{-1}$ (unless stated otherwise) on the surface of the bottle, sparged from the bottom with filtered $2 \%(\mathrm{v} / \mathrm{v}) \mathrm{CO}_{2}$-enriched air at $0.3-0.5 \mathrm{~L} \cdot \mathrm{min}^{-1}$ and maintained at $28 \pm 1{ }^{\circ} \mathrm{C}$. All cultures were started at an initial cell density $\left(\mathrm{OD}_{750 \mathrm{~nm}}\right)$ of 0.2 .

For the identification of sucrose-accumulating strains, microalgae were cultivated in BG11 medium containing $10 \mathrm{mM} \mathrm{NaNO}_{3}$ for 2 days after which $150 \mathrm{mM} \mathrm{NaCl}$ was added and then left to grow for another 2 days. Light intensity was set at $325 \mu \mathrm{mol}$.photons $\cdot \mathrm{m}^{-2} \cdot \mathrm{s}^{-1}$ on the surface of the bottles.

For algal cultivation in seawater, BG11 medium was prepared using synthetic seawater $\left(24.54 \mathrm{~g} \cdot \mathrm{L}^{-1} \mathrm{NaCl} ; 0,74 \mathrm{~g} \cdot \mathrm{L}^{-1} \mathrm{KCl} ; 1.90 \mathrm{~g} \cdot \mathrm{L}^{-1}\right.$ $\mathrm{MgCl}_{2} ; 1.47 \mathrm{~g} \cdot \mathrm{L}^{-1} \mathrm{CaCl}_{2} \cdot 2 \mathrm{H}_{2} \mathrm{O}, 6.16 \mathrm{MgSO}_{4} \cdot 7 \mathrm{H}_{2} \mathrm{O}, 0.84 \mathrm{~g} \cdot \mathrm{L}^{-1} \mathrm{NaHCO}_{3}$; $0.04 \mathrm{~g} \cdot \mathrm{L}^{-1} \mathrm{~K}_{2} \mathrm{HPO}_{4} ; 0.036 \mathrm{~g} \cdot \mathrm{L}^{-1} \mathrm{CaCl}_{2} \cdot 2 \mathrm{H}_{2} \mathrm{O} ; 0.006 \mathrm{~g} \cdot \mathrm{L}^{-1}$ citric acid; $0.006 \mathrm{~g} \cdot \mathrm{L}^{-1}$ ferric ammonium citrate; $0.001 \mathrm{~g} \cdot \mathrm{L}^{-1}$ EDTA (disodium salt); $0.02 \mathrm{~g} \cdot \mathrm{L}^{-1} \mathrm{Na}_{2} \mathrm{CO}_{3}$; and trace metal mix A5) and mixed at stated proportions with BG11 medium prepared in deionized water.

For simulation of outdoor cultivation, laboratory benchtop environmental photobioreactors (ePBRs Phenometrics ${ }^{\mathrm{TM}}$ ) were used [26]. To simulate 5-cm-depth ponds, ePBRs were filled with $90 \mathrm{~mL}$ of BG11 medium prepared in $25 \%(\mathrm{v} / \mathrm{v})$ seawater containing $10 \mathrm{mM} \mathrm{NaNO}_{3}$ and sparged during the daylight phase with $2 \%(\mathrm{w} / \mathrm{v}) \mathrm{CO}_{2}$ in air. ePBRs were programmed to simulate the mean summer season weather in Fortaleza, Brazil $\left(3^{\circ} 46^{\prime} 53^{\prime \prime}\right.$ S $38^{\circ} 35^{\prime} 20^{\prime \prime}$ O): maximum irradiance at noon of $1554 \mu \mathrm{mol}$ photons $\cdot \mathrm{m}^{-2} \cdot \mathrm{s}^{-1} ; 13 \mathrm{~h}$ day duration; and $28 \pm 3{ }^{\circ} \mathrm{C}$. Data was obtained from the Power Data Access Viewer from NASA (https://power.larc.nasa.gov). Both light and temperature were adjusted to a sinusoidal pattern from dusk to dawn. ePBRs were inoculated at an initial cell density $\left(\mathrm{OD}_{750 \mathrm{~nm}}\right)$ of 0.6 . After 2 days, the simulated ponds were flooded with $45 \mathrm{~mL}$ or $90 \mathrm{~mL}$ seawater-BG11medium to further induce sucrose accumulation for another 2 days. The resulting final pond depths were $7 \mathrm{~cm}$ or $10 \mathrm{~cm}$, respectively.

\subsection{Sucrose extraction and fermentation}

Two alternative methods were used for preparative sucrose extraction, essentially as described before [23]. Briefly, for the method based on microwaves (MW), the cell paste was subjected to extraction by microwaves at $200 \mathrm{w}$ of power, for 4 cycles of $2 \mathrm{~min}$ each, in a microwave oven (BGH Quick Chef ${ }^{\circledR}$ 15,140, Argentina). The soluble fraction was separated by centrifugation at $17,211 \times g$ for $15 \mathrm{~min}$. The extraction was repeated twice, and the fractions were combined. For the method based on dry milling (D\&M), the biomass was air-dried, milled with $15 \%$ sand $(w / \mathrm{w})$ and rehydrated with water at a 1:3.5 ratio $(w / v)$. After centrifugation at $11,952 \times g$ for $15 \mathrm{~min}$, the soluble fraction was separated, and the aqueous extraction was repeated one more time. Both soluble fractions were combined, incubated at $100{ }^{\circ} \mathrm{C}$ for $5 \mathrm{~min}$ and then centrifuged $16,300 \times g$ for 5 min to remove proteins.

Fermentations were conducted as previously described [4] by inoculating the sucrose-rich syrups with Saccharomyces cerevisiae for $24 \mathrm{~h}$ at $28{ }^{\circ} \mathrm{C}$ and agitation at $120 \mathrm{rpm}$.

\subsection{Analytical methods}

Cell density was estimated by periodically measuring the OD at $750 \mathrm{~nm}$ with a UV-1800 spectrophotometer (Shimadzu, Japan). To estimate doubling time, data were plotted and adjusted to theoretical curves of exponential growth using GraphPad PRISM software (Intuitive Software for Science, US). Dry weight was determined from $25 \mathrm{~mL}$ of suspended cells in culture medium. Samples were first centrifuged at $3900 \times g$ for $10 \mathrm{~min}$, transferred into $1.5 \mathrm{~mL}$ tubes and centrifuged again at $16,300 \times g$ for $5 \mathrm{~min}$, at $4{ }^{\circ} \mathrm{C}$. Pellets were dried in an oven at $90{ }^{\circ} \mathrm{C}$ until constant weight was reached (2-3 days).

For protein determination, samples were heated at $100{ }^{\circ} \mathrm{C}$ for $10 \mathrm{~min}$ in the presence of $1 \mathrm{~N} \mathrm{NaOH}$, followed by Lowry's method [27] using $\mathrm{NaOH}$-treated bovine serum albumin as a standard. For total lipids determination, lipids were extracted and determined gravimetrically based on Bligh and Dyer [28] with previously described modifications [24]. Alternatively, lipids were determined by the sulfophospho-vanillin method (SFV) [29] using commercial canola oil as a lipid standard.

For total carbohydrates determination, the anthrone reagent was used [30]. Analytical sucrose extraction/determination was performed essentially as previously described [31]. Briefly, 14 to $45 \mathrm{~mL}$ of culture was centrifuged at $3600 \times g$ for $15 \mathrm{~min}$, at $4{ }^{\circ} \mathrm{C}$. Cell pellets were resuspended in 2 volumes of boiling alkaline water $(\mathrm{pH} 8)$ and incubated at $100{ }^{\circ} \mathrm{C}$ for $5 \mathrm{~min}$, followed by centrifugation at $9600 \times g$ for $5 \mathrm{~min}$, at $4{ }^{\circ} \mathrm{C}$. These steps were repeated twice, and fractions were combined. Alternatively, extraction was done according to Waghmare and colleagues [32] with modifications. First, 1 to $3 \mathrm{~mL}$ of culture were centrifuged at $4800 \times g$ for $5 \mathrm{~min}$, at $4{ }^{\circ} \mathrm{C}$. Pellets were resuspended in $250 \mu \mathrm{L}$ PBS buffer $\left(8 \mathrm{mM} \mathrm{Na}_{2} \mathrm{HPO}_{4}, 2 \mathrm{mM} \mathrm{NaH}_{2} \mathrm{PO}_{4}, 140 \mathrm{mM} \mathrm{NaCl}\right.$, $\mathrm{pH}$ 7.4), and frozen and thawed 3 times. Then, one volume of anhydrous ethanol, previously warmed-up to $50{ }^{\circ} \mathrm{C}$, was added. Samples were vortexed and centrifuged at $4800 \times g$ for $10 \mathrm{~min}$, at $4{ }^{\circ} \mathrm{C}$. Steps were repeated twice, fractions were combined and left to evaporate under vacuum in a Speed Vac Concentrator (HVL, Savant ${ }^{\mathrm{TM}}$ ). Samples were resuspended in 0.5 or $1 \mathrm{~mL}$ of deionized water. Sucrose determination was done by incubating the samples at $55{ }^{\circ} \mathrm{C}$ in the presence of $80 \mu \mathrm{g} \cdot \mathrm{mL}^{-1}$ acid invertase (Sigma-Aldrich) and $10 \mathrm{mM} \mathrm{NaOAc}$, pH 4.5 for $30 \mathrm{~min}$. Conversion into glucose and fructose was determined by the Somogyi-Nelson's method with a standard curve using sucrose [31].

Ethanol was determined by an enzymatic assay as reported previously [4]. The standard ethanol assay contained $50 \mathrm{mM}$ Tris- $\mathrm{HCl}$, $\mathrm{pH} 8.4 ; 2.5 \mathrm{mM} \mathrm{NAD}^{+}$and $3 \mu \mathrm{g}$ protein preparations enriched in alcohol dehydrogenase activity. Ethanol dependent reduction of $\mathrm{NAD}^{+}$ was detected in a spectrophotometer at $340 \mathrm{~nm}$ and then compared with a standard curve made with $99 \%(v / v)$ analytical grade ethanol. 
Table 1

Bioprospecting for sucrose-accumulating microalgae strains.

\begin{tabular}{|c|c|c|c|c|}
\hline Strain & Dry weight $\left(g \cdot L^{-1}\right)$ & Sucrose (\% DW) & Sucrose productivity $\left(\mathrm{mg} \cdot \mathrm{L}^{-1} \cdot \mathrm{d}^{-1}\right)$ & Strain origin \\
\hline Ankistrodesmus sp. A14 & $1.39 \pm 0.06$ & $5.42 \pm 0.69$ & $18.80 \pm 3.36$ & {$[25]$} \\
\hline Ankistrodesmus sp. LP-1 & $1.01 \pm 0.37$ & $3.64 \pm 0.51$ & $9.66 \pm 4.68$ & [24] \\
\hline Ankistrodesmus sp. SP2-15 & $1.34 \pm 0.12$ & $5.20 \pm 0.26$ & $17.34 \pm 0.72$ & [24] \\
\hline Chlorella sorokiniana sp. $R P$ & $1.36 \pm 0.29$ & $4.57 \pm 0.39$ & $15.79 \pm 4.60$ & {$[24]$} \\
\hline Chlorella sp. $\mathrm{CH}$ & $1.34 \pm 0.12$ & $5.34 \pm 0.73$ & $18.16 \pm 4.04$ & [24] \\
\hline Chlorella sp. MI & $1.05 \pm 0.28$ & $4.13 \pm 0.51$ & $11.26 \pm 4.29$ & [24] \\
\hline Chlorella sp. Prm & $1.06 \pm 0.20$ & $7.26 \pm 2.34$ & $20.38 \pm 9.86$ & [25] \\
\hline Chlorella sp. Rys & $1.37 \pm 0.03$ & $3.98 \pm 0.89$ & $13.54 \pm 2.74$ & [25] \\
\hline Chlorella sp. SP2-1 & $1.24 \pm 0.20$ & $5.34 \pm 0.22$ & $16.63 \pm 3.35$ & [24] \\
\hline Chlorophyta sp. C1 & $1.51 \pm 0.16$ & $7.19 \pm 1.71$ & $26.04 \pm 3.21$ & [24] \\
\hline Chlorophyta sp. L-20 & $1.30 \pm 0.35$ & $5.58 \pm 1.18$ & $19.22 \pm 8.76$ & [24] \\
\hline Chlorophyta sp. SP1-20 & $1.69 \pm 0.22$ & $4.79 \pm 0.84$ & $19.79 \pm 0.93$ & [24] \\
\hline Chlorophyta sp. MH & $1.08 \pm 0.31$ & $6.81 \pm 0.44$ & $17.99 \pm 4.04$ & [24] \\
\hline Coelastrella sp. P2 & $1.09 \pm 0.13$ & $8.84 \pm 0.83$ & $23.75 \pm 0.75$ & {$[25]$} \\
\hline Desmodesmus sp. A1 & $0.44 \pm 0.01$ & $10.49 \pm 4.32$ & $11.89 \pm 5.17$ & {$[25]$} \\
\hline Desmodesmus sp. FG & $1.40 \pm 0.23$ & $4.76 \pm 1.01$ & $17.29 \pm 6.28$ & [24] \\
\hline Desmodesmus sp. $\mathrm{P} 1$ & $1.40 \pm 0.001$ & $5.98 \pm 0.55$ & $20.93 \pm 1.94$ & [25] \\
\hline Desmodesmus sp. P13 & $1.43 \pm 0.13$ & $6.43 \pm 0.35$ & $23.04 \pm 3.34$ & [25] \\
\hline Desmodesmus sp. P5 & $1.54 \pm 0.40$ & $10.94 \pm 1.11$ & $40.67 \pm 6.23$ & {$[25]$} \\
\hline Desmodesmus sp. P7 & $1.59 \pm 0.15$ & $7.34 \pm 0.04$ & $29.09 \pm 3.01$ & [25] \\
\hline Haematococcus pluvialis $\mathrm{HP}$ & $1.67 \pm 0.18$ & $6.10 \pm 0.21$ & $25.56 \pm 3.59$ & [24] \\
\hline Haematococcus pluvialis & $0.32 \pm 0.06$ & $3.86 \pm 1.15$ & $2.88 \pm 0.32$ & UTEX 2505 \\
\hline Pseudokirchneriella sp. C1D & $1.33 \pm 0.28$ & $7.68 \pm 0.44$ & $25.27 \pm 3.91$ & [24] \\
\hline Pseudokirchneriella sp. F21 & $1.73 \pm 0.07$ & $5.10 \pm 0.23$ & $21.99 \pm 0.14$ & {$[25]$} \\
\hline Pseudokirchneriella sp. P23 & $1.70 \pm 0.10$ & $5.49 \pm 0.51$ & $23.43 \pm 3.51$ & [25] \\
\hline Scenedesmus obliquss sp. C1S & $1.14 \pm 0.30$ & $5.31 \pm 1.41$ & $16.23 \pm 8.04$ & [24] \\
\hline Scenedesmus sp. F15 & $2.11 \pm 0.01$ & $7.80 \pm 0.30$ & $41.09 \pm 1.41$ & [25] \\
\hline Scenedesmus sp. P31 & $1.45 \pm 0.28$ & $4.81 \pm 1.79$ & $16.21 \pm 3.13$ & [25] \\
\hline Scenedesmus sp. RD & $1.51 \pm 0.19$ & $2.81 \pm 0.85$ & $11.01 \pm 4.53$ & [24] \\
\hline Selenastraceae sp. A3 & $1.49 \pm 0.08$ & $6.35 \pm 1.65$ & $23.38 \pm 4.86$ & [25] \\
\hline
\end{tabular}

\subsection{Statistical analysis}

To analyze the statistical significance of the difference in sucrose productivity in the experiment of salt stress priming, a $t$-test was performed using Sigma-Plot (Systat Software, Inc., US).

\section{Results and discussion}

\subsection{Bioprospecting for sucrose-accumulating microalgal strains}

Based on previous analyses of the properties of microalgal strains native to the Central [24] or Northern [25] regions of Argentina, we selected 29 freshwater strains, representing most genera of Chlorophyta, to identify sucrose-accumulating strains. Initially, all strains were challenged with a moderate salt stress at $150 \mathrm{mM} \mathrm{NaCl}$ for 2 days. Strains accumulated sucrose in the range of $2.8 \%$ to $11 \%(w / w)$ of their dry biomass (Table 1). While most of the strains accumulated sucrose at about $5 \%(w / w)$, only a few accumulated it over $10 \%(w / w)$. However, high sucrose accumulation does not necessarily translate into high sucrose productivity since it also depends on biomass productivity, which is affected by the strain's tolerance to salt stress. Under the standardized sucrose accumulation conditions used in this study (4 days, two under salt stress), the most productive strains were Desmodesmus sp. P5 and Scenedesmus sp. F15, which accumulated $41 \mathrm{mg}$ sucrose $\cdot \mathrm{L}^{-1} \cdot \mathrm{day}^{-1}$ and a final sucrose accumulation level in the biomass of $11 \pm 1 \%(\mathrm{w} / \mathrm{w})$ and $7.8 \pm 0.3 \%(\mathrm{w} / \mathrm{w})$, respectively (Table 1$)$.

Strains were cultivated in the presence of $10 \mathrm{mM} \mathrm{NaNO}_{3}$ for $48 \mathrm{~h}$ and induced with $150 \mathrm{mM} \mathrm{NaCl}$ for another $48 \mathrm{~h}$. Data represent the mean and range of two independent experiments.

Sucrose accumulation and sucrose metabolizing enzymes were described decades ago in some Chlorophytes [33]. However, to the best of our knowledge, the present study represents the first systematic effort to investigate the accumulation of sucrose in green algae. A literature survey indicated Neochloris oleoabundans as one of the most thoroughly studied strains with respect to sucrose accumulation as a response to salt stress [34]. This strain accumulates up to $4.8 \%(w / w)$ sucrose in its biomass [35], an average sucrose accumulator when compared to the strains analyzed in this study.

None of the genomes of the algal strains used in this study have been sequenced yet to allow a direct comparison of genes for sucrose metabolism. However, we have confirmed by BLAST analysis [36] the presence of sequences homologous to plant and cyanobacterial sucrosephosphate synthase and sucrose synthase genes [15] in the available draft genomes comprising most Chlorophytes (https://greenhouse.lanl. gov/greenhouse/organisms/). These results tend to confirm that sucrose metabolism in green algae would be as ubiquitous as it is in plants and cyanobacteria [15]. Furthermore, recent transcriptomic analyses showed up-regulation of sucrose metabolism genes in Chamydomonas reinhardtii [37] and $N$. oleoabundas [34] as a response to $\mathrm{NaCl}$ stress.

We previously showed that genetic engineering of a model cyanobacterium was necessary to increase sucrose accumulation up to $10 \%$ $(w / w)$ [23]. In the present study we identified promising native strains which accumulated about the same content of sucrose relative to transgenic cyanobacteria. As a sucrose-producing platform, native strains would represent an alternative likely to face fewer regulatory hurdles when compared to genetically engineered strains regarding potential environmental impacts [38].

\subsection{Effect of salt stress on microalgal growth and biochemical composition of the biomass}

Both Desmodesmus sp. P5 and Scenedesmus sp. F15, displaying the highest sucrose productivity at $41 \mathrm{mg}$ sucrose $\cdot \mathrm{L}^{-1} \cdot \mathrm{day}^{-1}$, and Pseudokirchneriella sp. C1D, as an example of a moderate accumulator ( $25 \mathrm{mg}$ sucrose $\cdot \mathrm{L}^{-1} \cdot \mathrm{day}^{-1}$ ) were selected for a more detailed analysis.

As expected for freshwater strains, higher salt concentrations negatively affected growth as ascertained by a decrease in $\mathrm{OD}_{750}$ (Fig. 1), an increase in doubling time, and a reduction of dry biomass production after 8 days (Table 2). Fig. 2 and Supplementary Fig. S1 show a time course of the effect of $\mathrm{NaCl}$ on the biochemical composition of the 
A

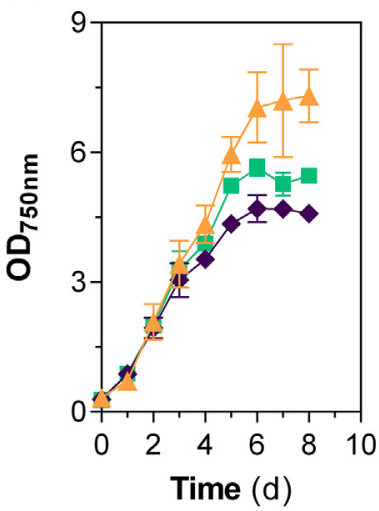

B

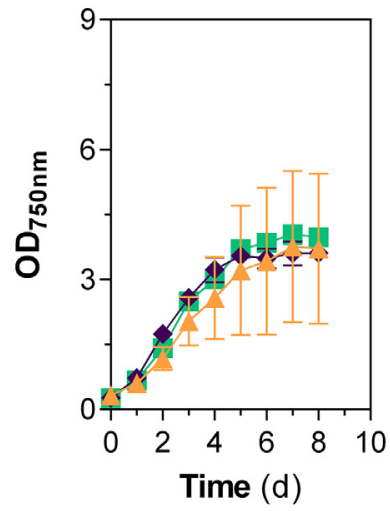

C

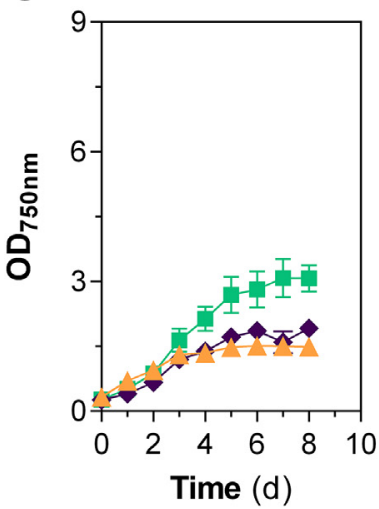

D

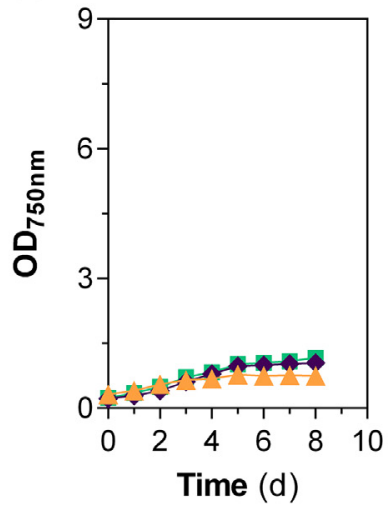

Fig. 1. Growth curves of $(\triangle)$ Pseudokirchneriella sp. C1D, ( $\square$ ) Desmodesmus sp. P5 and ( $\$$ Scenedesmus sp. F15 after 8 days of culture in BG11 medium containing $10 \mathrm{mM} \mathrm{NaNO}_{3}$ and (A) $0 \mathrm{mM}$, (B) $100 \mathrm{mM}$, (C) $200 \mathrm{mM}$, or (D) $400 \mathrm{mM}$ $\mathrm{NaCl}$. Data represent the mean and range of two independent experiments.

biomass of the selected microalgal strains. Generally, under non-stressing conditions all strains produced mainly crude protein and carbohydrates (Supplementary Fig. S1 A, C, E). To estimate biomass enrichment in each of the macromolecular fractions, total protein or carbohydrates productivities were normalized by culture density $\left(\mathrm{OD}_{750}\right)$. For all strains, these fractions remained mostly constant, independently of the salt concentration (Supplementary Fig. S2). Thus, volumetric productivity of these macromolecules was mostly constrained by the effect of $\mathrm{NaCl}$ on microalgal growth and overall biomass
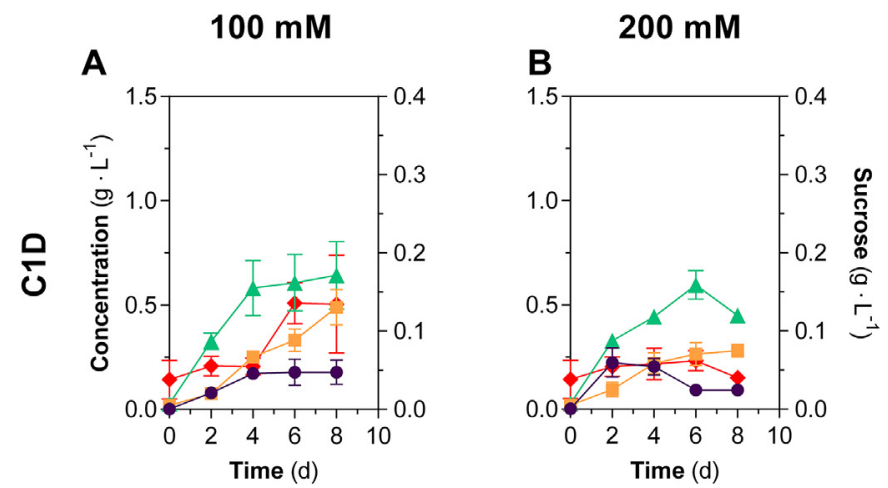

C

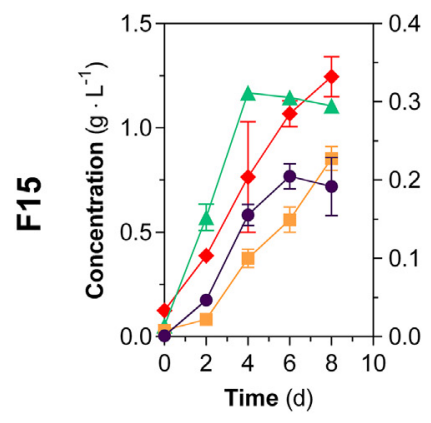

D

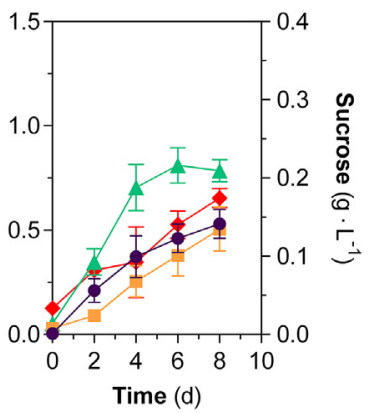

E
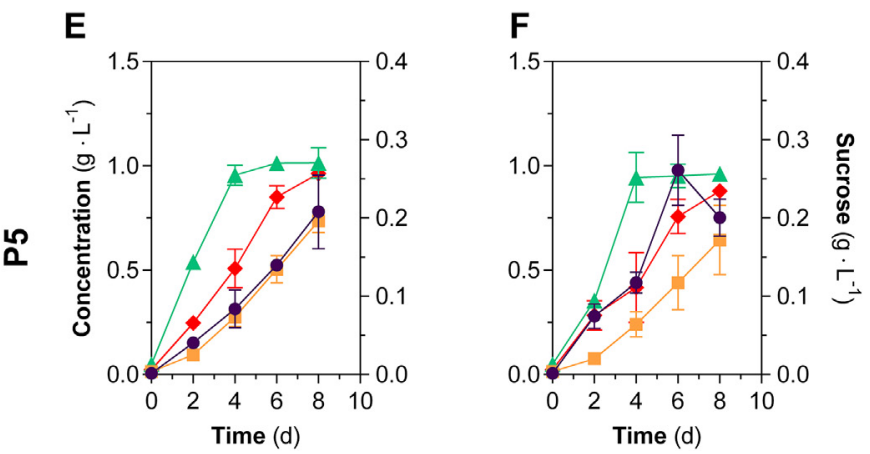

Fig. 2. Time course of $(\Delta)$ proteins, $(\diamond)$ total carbohydrates, $(\bullet)$ sucrose and $(\square)$ lipids accumulation in (A, B) Pseudokirchneriella sp. C1D; (C, D) Scenedesmus sp. F15; or (E, F) Desmodesmus sp. P5, in the presence of (A, C, E) $100 \mathrm{mM}$, or (B, D, F) $200 \mathrm{mM} \mathrm{NaCl}$. Data represent the mean and range of two independent experiments.

Table 2

Characterization of growth and final biomass composition of selected strains.

\begin{tabular}{|c|c|c|c|c|c|c|c|c|}
\hline Strain & $\begin{array}{l}\mathrm{NaCl} \\
(\mathrm{mM})\end{array}$ & Doubling time (d) & Dry weight $\left(g \cdot L^{-1}\right)$ & Protein (\% DW) & Lipid $^{\mathrm{a}}$ (\% DW) & Lipid $^{\mathrm{b}}$ (\% DW) & Carbohydrate (\% DW) & Sucrose (\% DW) \\
\hline \multirow[t]{4}{*}{ Pseudokirchneriella sp. C1D } & 0 & $0.8 \pm 0.2$ & $2.38 \pm 0.04$ & $46.3 \pm 7.0$ & $30.8 \pm 3.5$ & $31.3 \pm 0.9$ & $47 \pm 2$ & $2.6 \pm 0.3$ \\
\hline & 100 & $1.3 \pm 0.2$ & $1.4 \pm 0.4$ & $45.1 \pm 0.6$ & $35.2 \pm 3.4$ & $35 \pm 2$ & $33 \pm 8$ & $3.2 \pm 0.2$ \\
\hline & 200 & $1.6 \pm 0.1$ & $0.85 \pm 0.05$ & $53.1 \pm 4.9$ & $33.1 \pm 1.4$ & $42 \pm 2$ & $18 \pm 3$ & $2.9 \pm 0.6$ \\
\hline & 400 & $2.8 \pm 0.9$ & $0.4 \pm 0.1$ & $40.39^{c}$ & $21.8 \pm 1.2$ & $\mathrm{~N} / \mathrm{D}$ & $16 \pm 10$ & $6 \pm 1$ \\
\hline \multirow[t]{4}{*}{ Desmodesmus sp. P5 } & 0 & $0.9 \pm 0.2$ & $2.62 \pm 0.02$ & $42.9 \pm 1.0$ & $31.0 \pm 2.6$ & $24 \pm 3$ & $40 \pm 4$ & $4.2 \pm 0.2$ \\
\hline & 100 & $1.06 \pm 0.03$ & $2.53 \pm 0.02$ & $40.0 \pm 2.5$ & $29.0 \pm 2.3$ & $28 \pm 2$ & $38.1 \pm 0.4$ & $8 \pm 2$ \\
\hline & 200 & $1.2 \pm 0.1$ & $2.5 \pm 0.2$ & $38.8 \pm 3.0$ & $25.4 \pm 4.0$ & $29 \pm 1$ & $35 \pm 3$ & $8.0 \pm 0.2$ \\
\hline & 400 & $2.3 \pm 0.1$ & $1.63 \pm 0.02$ & $33.3 \pm 0.5$ & $26.3 \pm 3.6$ & $29 \pm 2$ & $37 \pm 3$ & $9.1 \pm 0.2$ \\
\hline \multirow[t]{4}{*}{ Scenedesmus sp. F15 } & 0 & $0.81 \pm 0.05$ & $2.66 \pm 0.07$ & $28.5 \pm 2.5$ & $26.5 \pm 4.4$ & $26.6 \pm 0.2$ & $51 \pm 4$ & $2.50 \pm 0.06$ \\
\hline & 100 & $0.77 \pm 0.08$ & $2.82 \pm 0.04$ & $39.2 \pm 0.4$ & $30.3 \pm 2.4$ & $28.62 \pm 0.03$ & $44 \pm 3$ & $7 \pm 1$ \\
\hline & 200 & $1.3 \pm 0.1$ & $1.8 \pm 0.1$ & $42.6 \pm 0.3$ & $27.1 \pm 2.3$ & $28 \pm 3$ & $35.5 \pm 0.3$ & $7.6 \pm 0.6$ \\
\hline & 400 & $2.1 \pm 0.1$ & $1.43 \pm 0.03$ & $37.0 \pm 2.5$ & $27.2 \pm 2.7$ & $33 \pm 1$ & $34 \pm 1$ & $5 \pm 3$ \\
\hline
\end{tabular}

Samples were collected after 8 days of culture.

Data represent the mean and range of two independent experiments.

a Determined with the SPV method.

b Determined gravimetrically. 
productivity (Fig. 1). Conversely, during salt stress, algal cells shifted towards sucrose and lipid accumulation (Fig. 2 and Supplementary Figs. S1 and S2). Although sucrose enrichment in the biomass was maximal at $400 \mathrm{mM} \mathrm{NaCl}$ in all strains (Table 2 and Supplementary Fig. S2J-L), sucrose productivity tended to decline at higher salt concentrations and longer times (Supplementary Fig. S3). Maximum sucrose productivities were $72 \mathrm{mg}$ sucrose $\cdot \mathrm{L}^{-1} \cdot \mathrm{day}^{-1}$ for Desmodesmus sp. P5 at $200 \mathrm{mM}$ from day 4 to $6 ; 54 \mathrm{mg}$ sucrose $\mathrm{L}^{-1}$. day ${ }^{-1}$ for Scenedesmus sp. F15 at $100 \mathrm{mM}$ $\mathrm{NaCl}$ from day 2 to 4 ; and $29 \mathrm{mg}$ sucrose $\cdot \mathrm{L}^{-1} \cdot \mathrm{day}^{-1}$ Pseudokirchneriella sp. C1D at $200 \mathrm{mM} \mathrm{NaCl}$ from day 0 to 2 (Supplementary Fig. S3). As a reference, sucrose productivity of $N$. oleoabundans was $7.1 \mathrm{mg}$ sucrose $\cdot \mathrm{L}^{-1} \cdot$ day $^{-1}$ when induced with a $\mathrm{NaCl}$ increase of $400 \mathrm{mM}$ from day 0 to 1, as recalculated from Band and co-workers (1992) [35]. However, the difference in culture conditions between both studies prevents a more direct comparison.

\subsection{Combined effect of $\mathrm{NaCl}$ and $\mathrm{N}$ on co-production of sucrose and lipids}

A previous work by our group showed that Desmodesmus sp. P5 is an oleaginous strain [25]. Here, we showed that this strain can also accumulate sucrose under moderate-to-high $\mathrm{NaCl}$ stress (Tables 1 and 2, Figs. 2 and Supplementary Fig. S1). Hence, we chose it to analyze the possibility of co-producing sucrose and lipids.

Since it is known that lipids accumulation in microalgae is normally triggered by $\mathrm{N}$ deficiency [39], we analyzed the combined effect of $\mathrm{NaCl}$ and $\mathrm{NaNO}_{3}$ on sucrose and total lipids accumulation by this strain. While the effect of $\mathrm{N}$-deficiency on lipids accumulation was more noticeable under non salt-stressing conditions (Fig. 3 A, C, E, G), accumulation levels tended to be almost identical when cells grew in the presence of $200 \mathrm{mM} \mathrm{NaCl}$, regardless of the availability of $\mathrm{N}$ (Fig. $3 \mathrm{~B}$, D, F, H). Additionally, sucrose productivity was attenuated under $\mathrm{N}$ deficiency (Fig. 3 A-D) due to a decrease in both biomass productivity (Table 3 and Supplementary Fig. S4 A-B) and accumulation of the sugar in the biomass (Table 3 and Supplementary Fig. S5 A-D). These results indicated that, under salt-stressing conditions, N-sufficiency ensures a reasonably high productivity of both lipids and sucrose (Table 3 and Fig. 3 F, H).

\subsection{Effect of acclimation to $\mathrm{NaCl}$ on sucrose and lipids productivity}

It is generally acknowledged that priming by prior exposure to an eliciting factor makes organisms more tolerant to future stress exposure [40]. Thus, we analyzed this aspect by culturing Desmodesmus sp. P5 first in the presence of $100 \mathrm{mM} \mathrm{NaCl}$ (acclimation) and then increasing $\mathrm{NaCl}$ concentration to $400 \mathrm{mM}$ (salt-stress). A three-day acclimation period was chosen since maximum growth rate is maintained for that period, at $100 \mathrm{mM} \mathrm{NaCl}$ (Fig. 1B). By doing this, we sought to maximize sucrose productivity per volume and days of culture. After 8 days of culture in the presence of $3 \mathrm{mM} \mathrm{NaNO}_{3}$, sucrose productivity of nonacclimated microalgae was $70 \mathrm{mg} \cdot \mathrm{L}^{-1}$ in the presence of $100 \mathrm{mM}$ (Fig. 4A) or $200 \mathrm{mM}$ (Fig. 3D), or $100 \mathrm{mg} \cdot \mathrm{L}^{-1}$ at $400 \mathrm{mM} \mathrm{NaCl}$ (Fig. 4B). Acclimated and stressed cells produced $130 \pm 8 \mathrm{mg} \mathrm{su}-$ crose $\mathrm{L}^{-1}$ (Fig. 4C) or $279 \pm 29 \mathrm{mg}$ sucrose $\mathrm{L}^{-1}$ (Fig. 4D) when supplied with 3 or $10 \mathrm{mM} \mathrm{NaNO}_{3}$, respectively; showing a an statistically statistically significant difference between N-deficiency and sufficiency ( $t$-test, $p<.001$ ). Thus, $\mathrm{N}$ sufficiency enabled a 2 -fold higher sucrose productivity, and acclimation to $\mathrm{NaCl}$ an additional $30 \%$ increase. Standardizing these data to the culture's cell density confirm sucrose accumulation under these conditions (Supplementary Fig. S6). Acclimation to $\mathrm{NaCl}$ decreased lipid productivity by $23 \%$ or $38 \%$ in the presence of $3 \mathrm{mM}$ (Fig. 4C) or $10 \mathrm{mM}$ (Fig. 4D) $\mathrm{NaNO}_{3}$, respectively, Supplementary Fig. S6.

Induction of sucrose accumulation in microalgae has been reported to take place soon after the onset of salt stress $[34,35]$. Rapid accumulation of sucrose in Chlorella emevsonii exposed to salt stress appeared to be independent of photosynthesis [41]. However, priming by
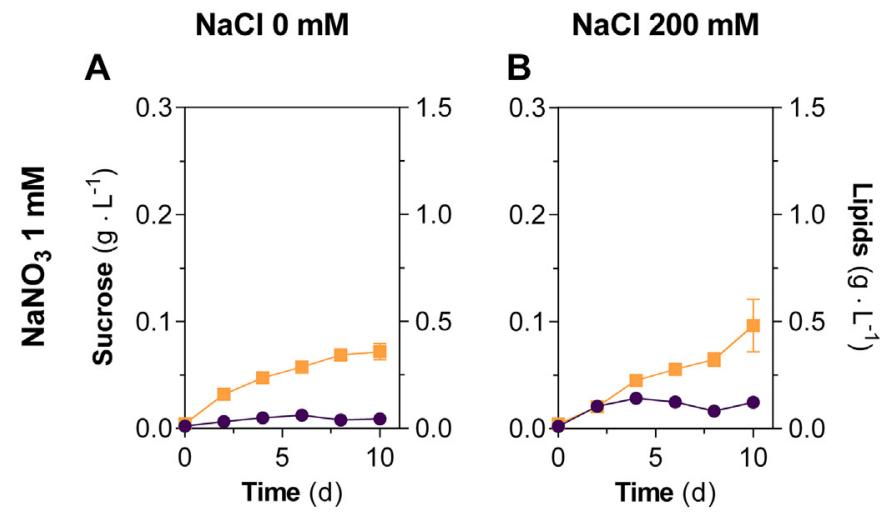

C
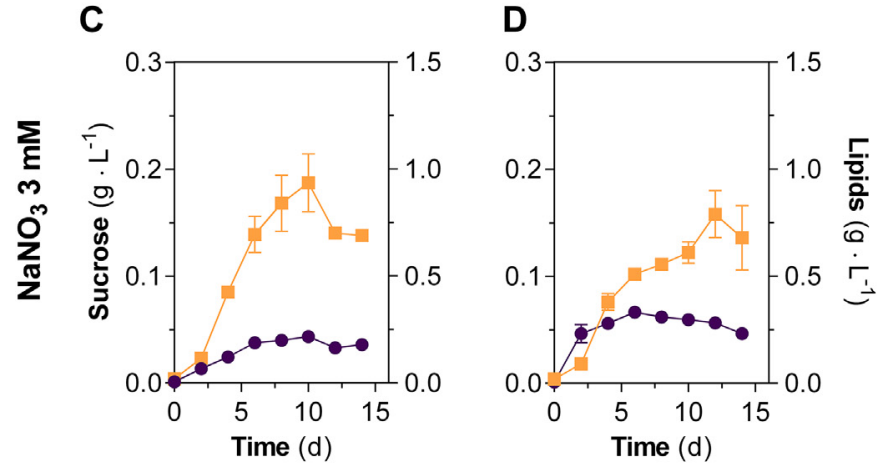

E

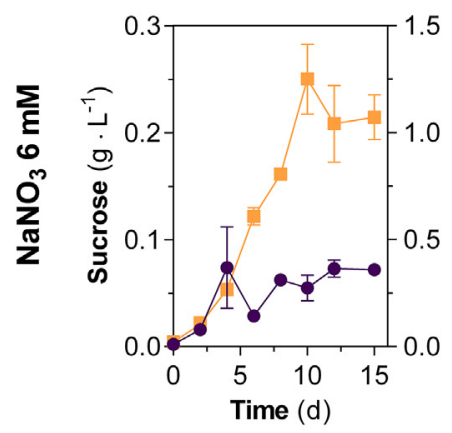

$\mathbf{F}$

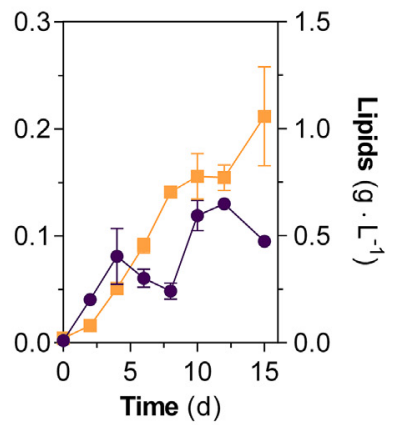

G

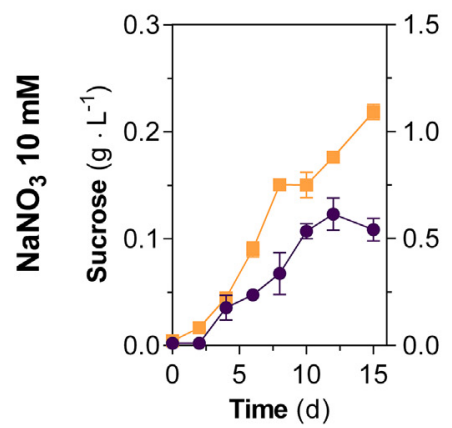

H

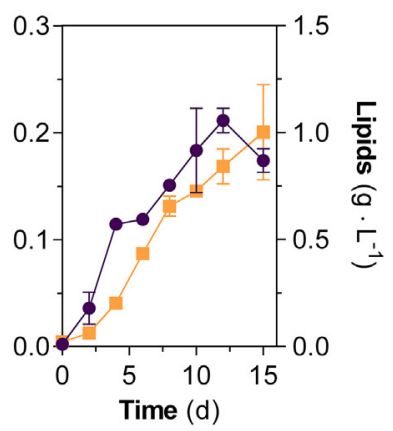

Fig. 3. Time course of $(\bullet)$ sucrose and $(\square)$ lipids accumulation of Desmodesmus sp. P5 cultivated in the presence of (A, C, E, G) $0 \mathrm{mM}$ or (B, D, F, H) $200 \mathrm{mM}$ $\mathrm{NaCl}$ and at the expense of (A, B) $1 \mathrm{mM}$; (C, D) $3 \mathrm{mM}$; (E,F) $6 \mathrm{mM}$; or (G, H) $10 \mathrm{mM} \mathrm{NaNO}$. Data represent the mean and range of two independent experiments.

a previous exposure to a low-stressing $\mathrm{NaCl}$ concentration appeared to result in an increased sucrose productivity by enabling a higher overall biomass productivity. Short-term acclimation of $C$. reinhardtii cells to $200 \mathrm{mM} \mathrm{NaCl}$ for 2 days resulted in upregulation of genes involved in the stress response, glycerophospholipid signaling, and genes for the transcription and translation machinery [37]. 
Table 3

Effect of $\mathrm{NaNO}_{3}$ and $\mathrm{NaCl}$ concentration on biomass composition of Desmodesmus sp. P5.

\begin{tabular}{|c|c|c|c|c|c|}
\hline $\mathrm{NaNO}_{3}(\mathrm{mM})$ & $\mathrm{NaCl}(\mathrm{mM})$ & Dry weight $\left(g \cdot L^{-1}\right)$ & Sucrose (\% DW) & Lipids $^{\mathrm{c}}$ (\% DW) & Lipids $^{\mathrm{d}}$ (\% DW) \\
\hline \multirow[t]{2}{*}{$1^{\mathrm{a}}$} & 0 & $0.88 \pm 0.04$ & $1.3^{\mathrm{e}}$ & $40 \pm 2$ & $27 \pm 5$ \\
\hline & 200 & $0.92 \pm 0.02$ & $2.64 \pm 0.01$ & $37.88^{\mathrm{e}}$ & $22 \pm 8$ \\
\hline \multirow[t]{2}{*}{$3^{b}$} & 0 & $2.01 \pm 0.04$ & $1.8 \pm 0.11$ & $35.62 \pm 0.05$ & ND \\
\hline & 200 & $1.90 \pm 0.04$ & $2.6 \pm 0.1$ & $38 \pm 10$ & ND \\
\hline \multirow[t]{2}{*}{$6^{\mathrm{b}}$} & 0 & $2.87 \pm 0.01$ & $2.52^{\mathrm{e}}$ & $37 \pm 4$ & $25 \pm 2$ \\
\hline & 200 & $2.92 \pm 0.03$ & $3.25 \pm 0.06$ & $36 \pm 7$ & $35.9 \pm 0.5$ \\
\hline \multirow[t]{2}{*}{$10^{\mathrm{b}}$} & 0 & $4 \pm 1$ & $2.7 \pm 0.4$ & $28 \pm 8$ & $17 \pm 5$ \\
\hline & 200 & $3.18 \pm 0.08$ & $5.5 \pm 0.5$ & $31 \pm 6$ & 31.53 \\
\hline
\end{tabular}

ND - not determined. Data represent the mean and range of two independent experiments.

a 10 days of culture.

b 15 days of culture.

c Determined with the SPV method.

d determined gravimetrically.

e Single determination.

\subsection{Effect of acclimation and induction of sucrose and lipids production by seawater}

Algal and cyanobacterial acclimation to $\mathrm{NaCl}$ have attracted considerable attention as a model system to better understand survival of organisms in saline environments and to gather insights towards the development of biotechnological alternatives to increase crops productivity in saline soils [42]. However, the real challenge for algal sucrose production would be to study the induction of its accumulation in freshwater microalgae with seawater [43,44]. In addition to $\mathrm{NaCl}$, seawater contains essential elements such as calcium, magnesium and potassium salts of sulfate and carbonate in a complex buffer system which normally supports microalgal growth [43].

Desmodesmus sp. P5 cells were acclimated in BG11 medium containing $100 \mathrm{mM} \mathrm{NaCl}$ and $10 \mathrm{mM} \mathrm{NaNO}_{3}$ for 3 days and then supplemented with one or three volumes of the same culture medium but prepared in artificial seawater. The final salt concentration was around $350 \mathrm{mM}$ or $475 \mathrm{mM}$, respectively. After 9 days, these cultures produced dry biomass at $3.9 \pm 0.3 \mathrm{~g} \cdot \mathrm{L}^{-1}$ or $3.0 \pm 0.2 \mathrm{~g} \cdot \mathrm{L}^{-1}$; and sucrose at $6.3 \pm 0.7 \%(w / w)$ or $10.3 \pm 0.4(\mathrm{w} / \mathrm{w})$, respectively. However, regardless of the almost two-fold increase of sucrose in the biomass of cultures containing a higher fraction of seawater, the overall sucrose productivity was fully compensated due to the higher biomass productivity of cultures induced with one volume of seawater (Fig. 5A and B).

\subsection{Sugar extraction from biomass and production of ethanol by fermentation}

We have previously optimized two methods for sugar extraction: one consisted in drying and milling (D\&M) the biomass, followed by an aqueous extraction at room temperature (about $22{ }^{\circ} \mathrm{C}$ ) and the other one was based on a microwaves (MW) treatment of the wet biomass [23]. Both methods allowed complete sucrose recoveries from the biomass of Desmodesmus sp. P5 at efficiencies of $145 \pm 5 \%$ and $154 \pm 10 \%$, respectively. These results indicate that the applied methods (i.e. D\&M or MW) are more efficient in extracting sucrose than the one used to determine the sucrose content in whole biomass. Higher concentrations of sucrose in the syrup could be obtained using the D\&M method (up to $3 \%(w / v)$ ), compared to the $1.5 \%(w / v)$ obtained by the MW method (Fig. 5C). An alternative strategy that has been improved over the last years involved over- and/or down-regulation of appropriate sucrose-metabolism genes and a sucrose exporter in cyanobacteria, for a final concentration of sucrose in the spent medium of $0.6 \%(\mathrm{w} / \mathrm{v})[45]$.

Sugar syrups prepared by either D\&M or MW methods, were quantitatively converted into ethanol by fermentation with $S$. cerevisiae at $15 \pm 1 \mathrm{~g} \cdot \mathrm{L}^{-1}$ or $7.8 \pm 0.3 \mathrm{~g} \cdot \mathrm{L}^{-1}$, respectively (Fig. $5 \mathrm{C}$ ). The efficiency of sucrose conversion into ethanol in $24 \mathrm{~h}$ was of $99 \%$ or $110 \%$ of the maximum theoretical value of $0.51 \mathrm{~g}$ ethanol $\cdot \mathrm{g}$ glucose ${ }^{-1}$, respectively. This is likely due to the presence of other fermentable sugars in the syrups.

High concentration of fermentable sugars in the syrup, minimally in the range of $8 \%(\mathrm{w} / \mathrm{v})$ is needed for the production of $40 \mathrm{~g}$ ethanol . $\mathrm{L}^{-1}$, which can be recovered by distillation at a competitive cost [46]. Thus, the present study represents a step forward towards the production of fermentation feedstocks from algal biomass without the need of biomass hydrolysis with acids and/or enzymes, promoting environmental safety and economic viability. This study focuses on its use for the production of ethanol; however, it can be used for the production of most fermentation products.
A

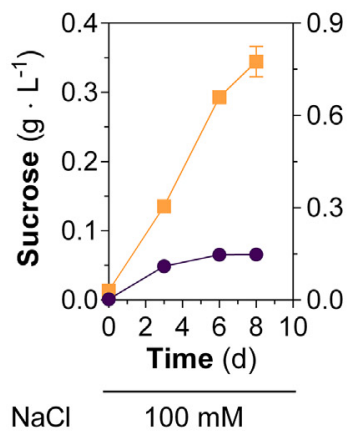

B

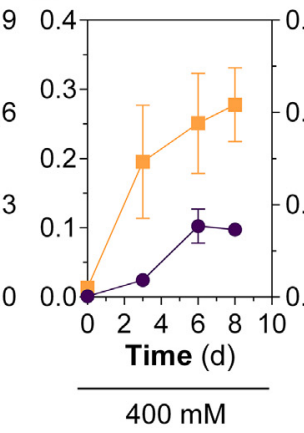

C

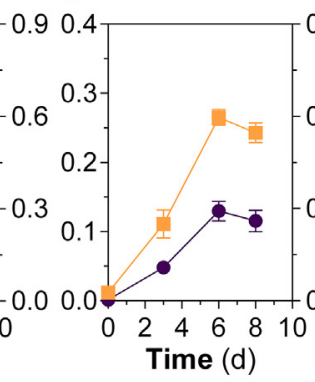

D

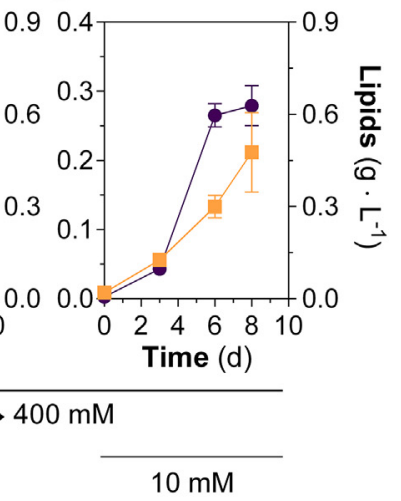

$10 \mathrm{mM}$
Fig. 4. Time course of $(\bullet)$ sucrose and ( $\square)$ lipids accumulation of Desmodesmus sp. P5 grown at the expense of (A-C) $3 \mathrm{mM}$ or (D) $10 \mathrm{mM} \mathrm{NaNO}_{3}$, and in the presence of (A) $100 \mathrm{mM} \mathrm{NaCl}$, (B) $400 \mathrm{mM} \mathrm{NaCl}$, or (C, D) acclimated to $100 \mathrm{mM} \mathrm{NaCl}$ and then induced with $400 \mathrm{mM} \mathrm{NaCl}$. Data represent the mean and standard deviation of two or three independent experiments.

$\mathrm{NaNO}_{3}$

$3 \mathrm{mM}$

$$
100
$$


A

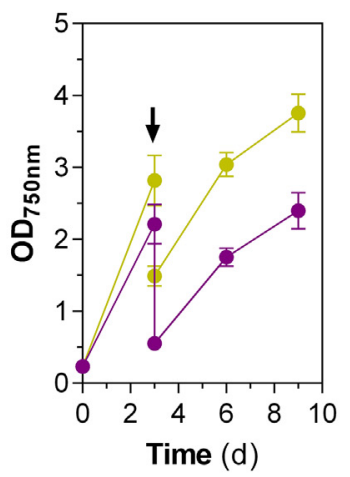

B

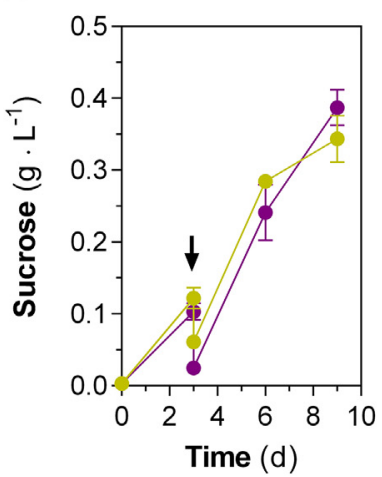

C

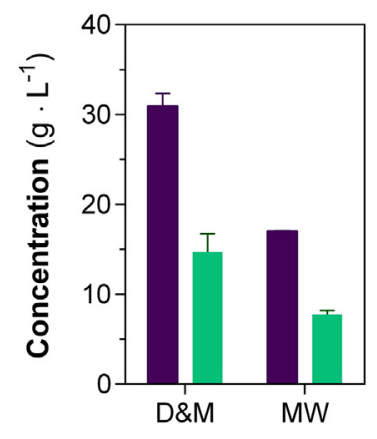

Fig. 5. (A) Growth curves of Desmodesmus sp. P5; and (B) time course of sucrose accumulation when cultures were supplemented with (๑) 1 or (•) 3 volumes of BG11 medium prepared in seawater (ASWO). Arrow indicates supplementation time point. Data point at day 2 after dilution in panel B was calculated, and not determined. Data represent the mean and standard deviation of three or four independent experiments. (C) Fermentation of sucrose extracts obtained by the drying and milling (D\&M) or the microwaves-based (MW) methods: ( $\square$ ) Initial sucrose concentration in the extracts and $(\square)$ ethanol produced after $24 \mathrm{~h}$ of fermentation by $S$. cerevisiae. Data represent the mean and range of two independent experiments.

\subsection{Algal biomass biorefinery for the recovery of other cellular fractions}

The microalgal strains used in this study, especially Desmodesmus sp. P5 accumulated lipids at about $30 \%(w / w)$ as a result of mild induction by $\mathrm{NaCl}$ (Tables 2 and 3 Supplementary Fig. S5), even in the presence of otherwise repressing concentrations of $\mathrm{NaNO}_{3}$. This aspect is very interesting since $\mathrm{N}$-deficiency largely increases lipids content in the biomass but offsets lipids productivity due to the decreasing algal proliferation and biomass production (Supplementary Fig. S4) [24,39,47].

It is broadly claimed that separation of multiple co-products in biomass biorefineries would largely improve third generation biofuels profitability [12]. The non-destructive methods used for separation of soluble sugars and crude protein would leave insoluble polysaccharides and lipids in the leftover biomass for further isolation by conventional methods for the extraction of feedstocks for biofuels and/or other applications. As recently proposed [23], separation of crude protein from the extracted aqueous phase by short pulses of heat could find applications as a feed supplement.

\subsection{Simulation of biomass and sucrose productivity in environmental photobioreactors}

To get a reasonably reliable model of ethanol productivity from microalgal biomass cultured in diluted seawater, we run Desmodesmus sp. P5 cultures in Phenometrics environmental Photobioreactors ${ }^{\mathrm{TM}}$ (ePBRs). ePBRs control LED-light intensity and temperature from a script of the corresponding weather variables for simulation of microalgal growth in open raceway ponds. These devises allow a low-risk and cost-effective way of modeling microalgal productivity at any geographical location [26]. Thus, we modeled biomass and sucrose productivity of Desmodesmus sp. strain P5 in Fortaleza (Brazil) in the summer season, which has been predicted as a potentially high productivity region by a mathematical model [48]. Similar to the continuous light experiments, cells were allowed to acclimate and grow in simulated $5 \mathrm{~cm}$-depth ponds containing 25\% seawater for 2 days, at which an $\mathrm{OD}_{750}$ of 2.3 was achieved. Preliminary experiments indicated that growth rate slowed down soon after and negatively affect final sucrose productivity (data not shown). Then, the simulated ponds were flooded with half or one volume of seawater supplemented with BG11 nutrients, including $10 \mathrm{mM} \mathrm{NaNO}$, for further induction of sucrose accumulation. These conditions corresponded to final proportions of seawater of $50 \%(v / v)(300 \mathrm{mM}$ salt $)$ or $63 \%(\mathrm{v} / \mathrm{v})(375 \mathrm{mM}$ salt), respectively. As expected, a higher proportion of seawater resulted in slower growth (Fig. 6A) and a lower final biomass concentration, also due to an increased dilution. Final dry biomass concentration after 4 days of culture was $1.69 \pm 0.08 \mathrm{~g} \cdot \mathrm{L}^{-1}$ or $1.14 \pm 0.06 \mathrm{~g} \cdot \mathrm{L}^{-1}$ for cultures at $50 \%(\mathrm{v} / \mathrm{v})$ or $63 \%(\mathrm{v} / \mathrm{v})$ seawater, respectively. Sucrose production was largely enhanced by dilution with seawater (Fig. 6B) for a final concentration in the dry biomass of $10.1 \pm 0.7 \%(w / w)$ or $8.3 \pm 0.4 \%(\mathrm{w} / \mathrm{w})$ for cultures induced with $50 \%(\mathrm{v} / \mathrm{v})$ or $63 \%(\mathrm{v} / \mathrm{v})$ seawater, respectively. This short-cycle cultivation program, comprising a first step for biomass production and acclimation to salt and a second step for enhanced induction of sucrose accumulation resulted in the highest productivity of sugar of the platform. The calculated biomass and sucrose productivities for the $50 \%(\mathrm{v} / \mathrm{v})$ seawater model were $18.0 \pm 0.8 \mathrm{~g} \cdot \mathrm{m}^{-2} \cdot \mathrm{day}^{-1}$, and $1.79 \pm 0.06 \mathrm{~g} \cdot \mathrm{m}^{-2} \cdot \mathrm{day}^{-1}$, respectively, which can be extrapolated to $66 \mathrm{MT} \cdot \mathrm{ha}^{-1} \cdot \mathrm{year}^{-1}$ or 6.5 MT.ha ${ }^{-1}$ year $^{-1}$ (Fig. 6C), assuming a very low seasonal variation in productivity in the modeled location, according to public weather historical records (https://power.larc.nasa.gov). Additionally, the $50 \%$ (v/v) seawater model would allow lower biomass collection costs due the higher biomass concentrations achieved when compared to the $63 \%$ (v/v) seawater model [49].

As demonstrated in this study, sucrose can be extracted from Desmodesmus sp. strain P5 biomass by mild methods, bypassing the need of hazardous chemicals and/or expensive enzymes for biomass saccharification, and converted into ethanol by common fermentation technology at a $100 \%$ efficiency. This would render an alcohol productivity of about $4200 \mathrm{~L}$ ethanol.ha ${ }^{-1} \cdot$ year $^{-1}$, which compares very well with productivity from sugarcane or sugar beet at $6800 \mathrm{~L}$ ethanol'ha ${ }^{-1} \cdot$ year $^{-1}$ or $5100 \mathrm{~L}$ ethanol'ha ${ }^{-1} \cdot$ year $^{-1}$, respectively [50].

Prospects of this alternative would be remarkable for different reasons. $i$ ) This platform relies mostly on the use of seawater for a considerable improvement of the water footprint of agricultural production; ii) it avoids the use of chemicals and/or enzymes for saccharification; and iii) alcohol production from about $10 \%$ of the biomass, leaves the rest of the cellular fractions (crude protein, polysaccharides and lipids) available as feedstocks for biofuels, feed, or other applications. Recently, we presented results that suggested that fermentation of carbohydrate-rich microalgal biomass, saccharified with diluted $\mathrm{H}_{2} \mathrm{SO}_{4}$ at $120{ }^{\circ} \mathrm{C}$ produces at least $7600 \mathrm{~L}$ ethanol'ha ${ }^{-1}$.year ${ }^{-1}$. This represents a promising alternative to corn kernel bioethanol production at typical productivities of about $4000 \mathrm{~L}$ ethanol.ha ${ }^{-1}$.year ${ }^{-1}$ [8]. That same report showed full recycling of the ethanol fermentation vinasse as nutrients for the cultivation of microalgae, enabling savings in fertilizers and lowering the environmental impact of the proposed production platform [8].

Nevertheless, and beyond the likely high potential productivity of the proposed platform and the advantages of circumventing biomass saccharification, more general cost associated with production of algal biomass would still need to be improved for economic feasibility compared to sugarcane or corn ethanol [12].

\section{Conclusion}

This study identifies useful microalgal strains and provides optimized conditions for sucrose production using seawater. Independence from saccharification and efficient conversion into ethanol by mild methods at a modeled productivity of $4200 \mathrm{~L}$ ethanol.ha ${ }^{-1}$.year ${ }^{-1}$ would place this platform as an alternative to ethanol production from 
A

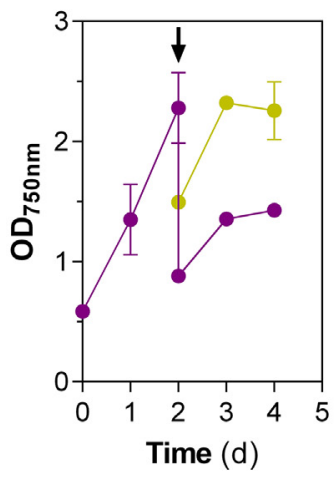

B

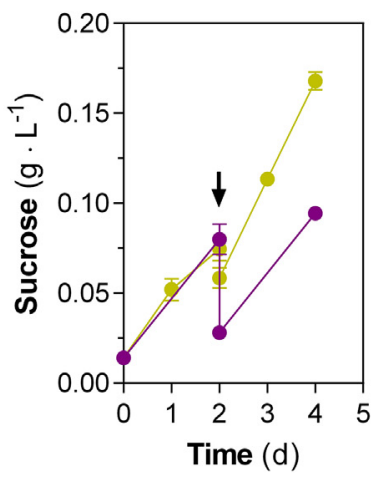

C

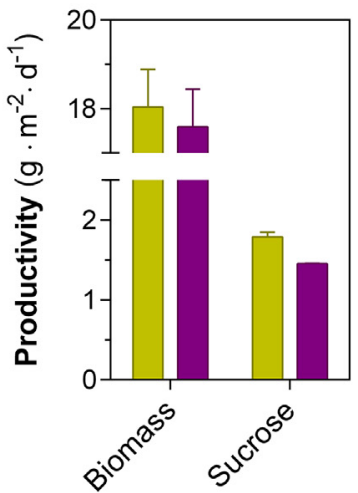

Fig. 6. (A) Growth curves of Desmodesmus sp. P5, (B) time course of sucrose accumulation, and (C) areal productivity when cultures were carried out in BG11 medium prepared in (॰) $50 \%$ or (๑) $63 \%$ seawater (ASWO). Arrow indicates supplementation time point. Data represent the mean and range of two independent experiments. conventional crops and agricultural systems. Both the mild conditions used for sugar and protein extraction, and increased lipids productivity in seawater under N-sufficiency conditions would largely favor the development of algal biomass biorefineries towards economic feasibility.

\section{Declaration of competing interest}

None.

\section{Acknowledgements}

The authors are very grateful to $\mathrm{M}$ Do Nascimento for helpful discussions and $\mathrm{N}$ Almada for technical assistance. This work was supported by the Agencia Nacional de Promoción Científica y Tecnológica, Argentina [grants numbers PICT2012-2589 and PICT2015-3559] to LC.

\section{Contributions}

MESS and CDC performed all experiments, analyzed results, prepared figures and collaborated in writing the manuscript. GLS contributed with funding. LC conceived and designed the experiments, supervised data analysis and interpretation, wrote the manuscript and contributed with funding.

\section{Statement of informed consent, human/animal rights}

No conflicts, informed consent, or human or animal rights are applicable to this study.

\section{Appendix A. Supplementary data}

Supplementary data to this article can be found online at https:// doi.org/10.1016/j.algal.2019.101733.

\section{References}

[1] M. Kousoulidou, L. Lonza, Biofuels in aviation: fuel demand and $\mathrm{CO}_{2}$ emissions evolution in Europe toward 2030, Transp. Res. Part D: Transp. Environ. 46 (2016) 166-181, https://doi.org/10.1016/j.trd.2016.03.018.

[2] J. Baeyens, Q. Kang, L. Appels, R. Dewil, Y. Lv, T. Tan, Challenges and opportunities in improving the production of bio-ethanol, Prog. Energy Combust. Sci. 47 (2015) 60-88, https://doi.org/10.1016/j.pecs.2014.10.003.

[3] C. Zhang, Lignocellulosic Ethanol: Technology and Economics, IntechOpen, 2019, https://doi.org/10.5772/intechopen.86701.

[4] L. Sanchez Rizza, M.E. Sanz Smachetti, M. Do Nascimento, G.L. Salerno, L. Curatti, Bioprospecting for native microalgae as an alternative source of sugars for the production of bioethanol, Algal Res. 22 (2017) 140-147, https://doi.org/10.1016/ j.algal.2016.12.021.

[5] M.E. Sanz Smachetti, L. Sanchez Rizza, C.D. Coronel, M.D. Nascimento, L. Curatti, Microalgal Biomass as an Alternative Source of Sugars for the Production of Bioethanol, Scrivener Publishing LLC, 2018, https://doi.org/10.1002/
9781119460381.

[6] L. Chaudhary, P. Pradhan, N. Soni, P. Singh, A. Tiwari, Algae as a feedstock for bioethanol production: new entrance in biofuel world, Int. J. ChemTech Res. 6 (2014) 1381-1389.

[7] D. Hernández, B. Riaño, M. Coca, M. García-González, Saccharification of carbohydrates in microalgal biomass by physical, chemical and enzymatic pre-treatments as a previous step for bioethanol production, Chem. Eng. J. 262 (2015) 939-945, https://doi.org/10.1016/j.cej.2014.10.049.

[8] L. Sanchez Rizza, C.D. Coronel, M.E. Sanz Smachetti, M. Do Nascimento, L. Curatti, A semi-closed loop microalgal biomass production-platform for ethanol from renewable sources of nitrogen and phosphorous, J. Clean. Prod. 219 (2019) 217-224, https://doi.org/10.1016/j.jclepro.2019.01.311.

[9] J.C. Quinn, R. Davis, The potentials and challenges of algae based biofuels: a review of the techno-economic, life cycle, and resource assessment modeling, Bioresour. Technol. 184 (2015) 444-452, https://doi.org/10.1016/j.biortech.2014.10.075.

[10] M. Huesemann, A. Chavis, S. Edmundson, D. Rye, S. Hobbs, N. Sun, M. Wigmosta, Climate-simulated raceway pond culturing: quantifying the maximum achievable annual biomass productivity of Chlorella sorokiniana in the contiguous USA, J. Appl. Phycol. 30 (2018) 287-298, https://doi.org/10.1007/s10811-017-1256-6.

[11] J. Yang, M. Xu, X. Zhang, Q. Hu, M. Sommerfeld, Y. Chen, Life-cycle analysis on biodiesel production from microalgae: water footprint and nutrients balance, Bioresour. Technol. 102 (2011) 159-165, https://doi.org/10.1016/j.biortech.2010. 07.017.

[12] L.M.L. Laurens, J. Markham, D.W. Templeton, E.D. Christensen, S. Van Wychen, E.W. Vadelius, M. Chen-Glasser, T. Dong, R. Davis, P.T. Pienkos, Development of algae biorefinery concepts for biofuels and bioproducts; a perspective on processcompatible products and their impact on cost-reduction, Energy Environ. Sci. 10 (2017) 1716-1738, https://doi.org/10.1039/C7EE01306J.

[13] D. Domozych, M. Ciancia, J.U. Fangel, M.D. Mikkelsen, P. Ulvskov, W.G. Willats, The cell walls of green algae: a journey through evolution and diversity, Front. Plant Sci. 3 (2012) 82, https://doi.org/10.3389/fpls.2012.00082.

[14] D.S. Domozych, Algal cell walls, eLS, John Wiley and Sons, Chichester, 2011.

[15] G.L. Salerno, L. Curatti, Origin of sucrose metabolism in higher plants: when, how and why? Trends Plant Sci. 8 (2003) 63-69, https://doi.org/10.1016/S13601385(02)00029-8.

[16] M.d.P. Bremauntz, L.G. Torres-Bustillos, R.-O. Cañizares-Villanueva, E. DuranParamo, L. Fernández-Linares, Trehalose and sucrose Osmolytes accumulated by algae as potential raw material for bioethanol, Natural Resources 2 (2011) 173-179, https://doi.org/10.4236/nr.2011.23023.

[17] W.L. Marques, V. Raghavendran, B.U. Stambuk, A.K. Gombert, Sucrose and Saccharomyces cerevisiae: a relationship most sweet, FEMS Yeast Res. 16 (2016), https://doi.org/10.1093/femsyr/fov107.

[18] G.L. Salerno, A.C. Porchia, W.A. Vargas, P.L. Abdian, Fructose-containing oligosaccharides: novel compatible solutes in Anabaena cells exposed to salt stress, Plant Sci. 167 (2004) 1003-1008, https://doi.org/10.1016/j.plantsci.2004.05.029.

[19] M.A. Kolman, G.L. Salerno, Sucrose in bloom-forming cyanobacteria: loss and gain of genes involved in its biosynthesis, Environ. Microbiol. 18 (2016) 439-449, https://doi.org/10.1111/1462-2920.13071.

[20] D.C. Ducat, J.A. Avelar-Rivas, J.C. Way, P.A. Silver, Rerouting carbon flux to enhance photosynthetic productivity, Appl. Environ. Microbiol. 78 (2012) 2660-2668, https://doi.org/10.1128/AEM.07901-11.

[21] W. Du, F. Liang, Y. Duan, X. Tan, X. Lu, Exploring the photosynthetic production capacity of sucrose by cyanobacteria, Metab. Eng. 19 (2013) 17-25, https://doi. org/10.1016/j.ymben.2013.05.001.

[22] F. Kirsch, Q. Luo, X. Lu, M. Hagemann, Inactivation of invertase enhances sucrose production in the cyanobacterium Synechocystis sp. PCC 6803, Microbiology 164 (2018) 1220-1228, https://doi.org/10.1099/mic.0.000708.

[23] M.E. Sanz Smachetti, M. Perez Cenci, G.L. Salerno, L. Curatti, Ethanol and protein production from minimally processed biomass of a genetically-modified cyanobacterium over-accumulating sucrose, Bioresource Technology Reports 5 (2019) 230-237, https://doi.org/10.1002/9781119460381.

[24] M. Do Nascimento, J.C. Ortiz-Marquez, L. Sanchez-Rizza, M.M. Echarte, L. Curatti, Bioprospecting for fast growing and biomass characterization of oleaginous microalgae from south-eastern Buenos Aires, Argentina, Bioresour. Technol. 125 
(2012) 283-290, https://doi.org/10.1016/j.biortech.2012.08.057.

[25] C.D. Coronel, M. Do Nascimento, L. Curatti, Effect of matching microalgal strains origin and regional weather condition on biomass productivity in environmental photobioreactors, Bioresource Technology Reports 5 (2019) 104-112, https://doi. org/10.1016/j.biteb.2018.12.006.

[26] B.F. Lucker, C.C. Hall, R. Zegarac, D.M. Kramer, The environmental photobioreactor (ePBR): an algal culturing platform for simulating dynamic natural environments, Algal Res. 6 (2014) 242-249, https://doi.org/10.1016/j.algal.2013.12. 007.

[27] O.H. Lowry, N.J. Rosebrough, A.L. Farr, R.J. Randall, Protein measurement with the Folin phenol reagent, J. Biol. Chem. 193 (1951) 265-275.

[28] E.G. Bligh, W.J. Dyer, A rapid method of total lipid extraction and purification, Can. J. Biochem. Physiol. 37 (1959) 911-917, https://doi.org/10.1139/y59-099.

[29] S.K. Mishra, W.I. Suh, W. Farooq, M. Moon, A. Shrivastav, M.S. Park, J.-W. Yang, Rapid quantification of microalgal lipids in aqueous medium by a simple colorimetric method, Bioresour. Technol. 155 (2014) 330-333, https://doi.org/10.1016/ j.biortech.2013.12.077.

[30] R. Dreywood, Qualitative test for carbohydrate material, Industrial \& Engineering Chemistry Analytical Edition 18 (1946) 499, https://doi.org/10.1021/ i560156a015.

[31] H.G. Pontis, Methods for Analysis of Carbohydrate Metabolism in Photosynthetic Organisms: Plants, Green Algae and Cyanobacteria, Academic Press, 2017.

[32] A.G. Waghmare, M.K. Salve, J.G. LeBlanc, S.S. Arya, Concentration and characterization of microalgae proteins from Chlorella pyrenoidosa, Bioresources and Bioprocessing 3 (2016) 16, https://doi.org/10.1186/s40643-016-0094-8.

[33] W.R. Duran, H.G. Pontis, Sucrose metabolism in green algae I. the presence of sucrose synthetase and sucrose phosphate synthetase, Mol. Cell. Biochem. 16 (1977) 149-152, https://doi.org/10.1007/BF01732056.

[34] L. de Jaeger, B.M. Carreres, J. Springer, P.J. Schaap, G. Eggink, V.A.P. Martins Dos Santos, R.H. Wijffels, D.E. Martens, Neochloris oleoabundans is worth its salt: Transcriptomic analysis under salt and nitrogen stress, PLoS One 13 (2018) e0194834-e0194834, , https://doi.org/10.1371/journal.pone.0194834.

[35] C.J. Band, B.O. Arredondo-Vega, R. Vazquez-Duhalt, H. Greppin, Effect of a saltosmotic upshock on the edaphic microalga Neochloris oleoabundans, Plant Cell Environ. 15 (1992) 129-133, https://doi.org/10.1111/j.1365-3040.1992. tb01466.x.

[36] S.F. Altschul, T.L. Madden, A.A. Schäffer, J. Zhang, Z. Zhang, W. Miller, D.J. Lipman, Gapped BLAST and PSI-BLAST: a new generation of protein database search programs, Nucleic Acids Res. 25 (1997) 3389-3402, https://doi.org/10. 1093/nar/25.17.3389.

[37] N. Wang, Z. Qian, M. Luo, S. Fan, X. Zhang, L. Zhang, Identification of salt stress responding genes using Transcriptome analysis in green alga Chlamydomonas reinhardtii, Int. J. Mol. Sci. 19 (2018) 3359, https://doi.org/10.3390/ijms19113359.

[38] W.J. Henley, R.W. Litaker, L. Novoveská, C.S. Duke, H.D. Quemada, R.T. Sayre, Initial risk assessment of genetically modified (GM) microalgae for commodity-scale biofuel cultivation, Algal Res. 2 (2013) 66-77, https://doi.org/10.1016/j.algal. 2012.11.001.

[39] Q. Hu, M. Sommerfeld, E. Jarvis, M. Ghirardi, M. Posewitz, M. Seibert, A. Darzins, Microalgal triacylglycerols as feedstocks for biofuel production: perspectives and advances, Plant J. 54 (2008) 621-639, https://doi.org/10.1111/j.1365-313X.2008. 03492.x.

[40] G. Tanou, V. Fotopoulos, A. Molassiotis, Priming against environmental challenges and proteomics in plants: update and agricultural perspectives, Front. Plant Sci. 3 (2012), https://doi.org/10.3389/fpls.2012.00216.

[41] H. Greenway, T. Setter, Accumulation of Proline and sucrose during the first hours after transfer of chlorella emevsonii to high NaCl, Funct. Plant Biol. 6 (1979) 69-79, https://doi.org/10.1071/PP9790069.

[42] N. Erdmann, M. Hagemann, Salt acclimation of algae and cyanobacteria: A comparison, in: L.C. Rai, J.P. Gaur (Eds.), Algal Adaptation to Environmental Stresses: Physiological, Biochemical and Molecular Mechanisms, Springer Berlin Heidelberg, Berlin, Heidelberg, 2001, pp. 323-361, , https://doi.org/10.1007/978-3-64259491-5_11.

[43] N. Arora, A. Patel, M. Sharma, J. Mehtani, P.A. Pruthi, V. Pruthi, K.M. Poluri, Insights into the enhanced lipid production characteristics of a fresh water microalga under high salinity conditions, Ind. Eng. Chem. Res. 56 (2017) 7413-7421, https://doi.org/10.1021/acs.iecr.7b00841.

[44] S.B. Ummalyma, R.K. Sukumaran, A. Pandey, Evaluation of Freshwater Microalgal Isolates for Growth and Oil Production in Seawater Medium, Waste and Biomass Valorization, (2018), pp. 1-8, https://doi.org/10.1007/s12649-018-0393-8.

[45] B.W. Abramson, J. Lensmire, Y.-T. Lin, E. Jennings, D.C. Ducat, Redirecting carbon to bioproduction via a growth arrest switch in a sucrose-secreting cyanobacterium, Algal Res. 33 (2018) 248-255, https://doi.org/10.1016/j.algal.2018.05.013.

[46] K.B. Möllers, D. Cannella, H. Jørgensen, N.-U. Frigaard, Cyanobacterial biomass as carbohydrate and nutrient feedstock for bioethanol production by yeast fermentation, Biotechnology for Biofuels 7 (2014) 64, https://doi.org/10.1186/1754-68347-64.

[47] G. Dragone, B.D. Fernandes, A.P. Abreu, A.A. Vicente, J.A. Teixeira, Nutrient limitation as a strategy for increasing starch accumulation in microalgae, Appl. Energy 88 (2011) 3331-3335, https://doi.org/10.1016/j.apenergy.2011.03.012.

[48] J.W. Moody, C.M. McGinty, J.C. Quinn, Global evaluation of biofuel potential from microalgae, Proc. Natl. Acad. Sci. 111 (2014) 8691-8696, https://doi.org/10.1073/ pnas.1321652111.

[49] D. Vandamme, I. Foubert, K. Muylaert, Flocculation as a low-cost method for harvesting microalgae for bulk biomass production, Trends Biotechnol. 31 (2013) 233-239, https://doi.org/10.1016/j.tibtech.2012.12.005.

[50] L. Panella, S.R. Kaffka, Sugar Beet (Beta vulgaris L) as a Biofuel Feedstock in the United States, Sustainability of the Sugar and Sugar-Ethanol Industries, American Chemical Society, 2010, pp. 163-175, https://doi.org/10.1021/bk-2010-1058. ch010. 